\title{
8
}
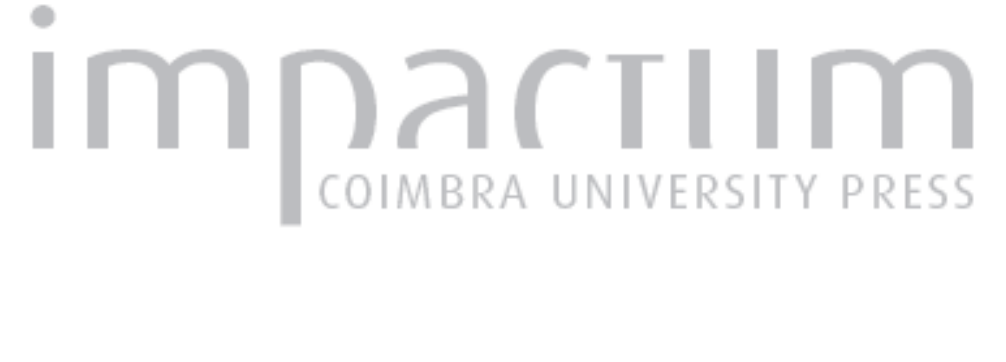

\section{Reequacionamento da concepção de natureza humana como fundamento do direito natural}

\author{
Autor(es): $\quad$ Bugallo Alvarez, Alejandro
}

Publicado por: Universidade Católica de Petrópolis; Instituto Brasileiro de Informação \section{em Ciência e Tecnologia}

URL

persistente:

DOI: $\quad$ DOI:http://dx.doi.org/10.14195/1984-6754_1-2_1

Accessed : $\quad$ 26-Apr-2023 14:19:48

A navegação consulta e descarregamento dos títulos inseridos nas Bibliotecas Digitais UC Digitalis, UC Pombalina e UC Impactum, pressupõem a aceitação plena e sem reservas dos Termos e Condições de Uso destas Bibliotecas Digitais, disponíveis em https://digitalis.uc.pt/pt-pt/termos.

Conforme exposto nos referidos Termos e Condições de Uso, o descarregamento de títulos de acesso restrito requer uma licença válida de autorização devendo o utilizador aceder ao(s) documento(s) a partir de um endereço de IP da instituição detentora da supramencionada licença.

Ao utilizador é apenas permitido o descarregamento para uso pessoal, pelo que o emprego do(s) título(s) descarregado(s) para outro fim, designadamente comercial, carece de autorização do respetivo autor ou editor da obra.

Na medida em que todas as obras da UC Digitalis se encontram protegidas pelo Código do Direito de Autor e Direitos Conexos e demais legislação aplicável, toda a cópia, parcial ou total, deste documento, nos casos em que é legalmente admitida, deverá conter ou fazer-se acompanhar por este aviso. 

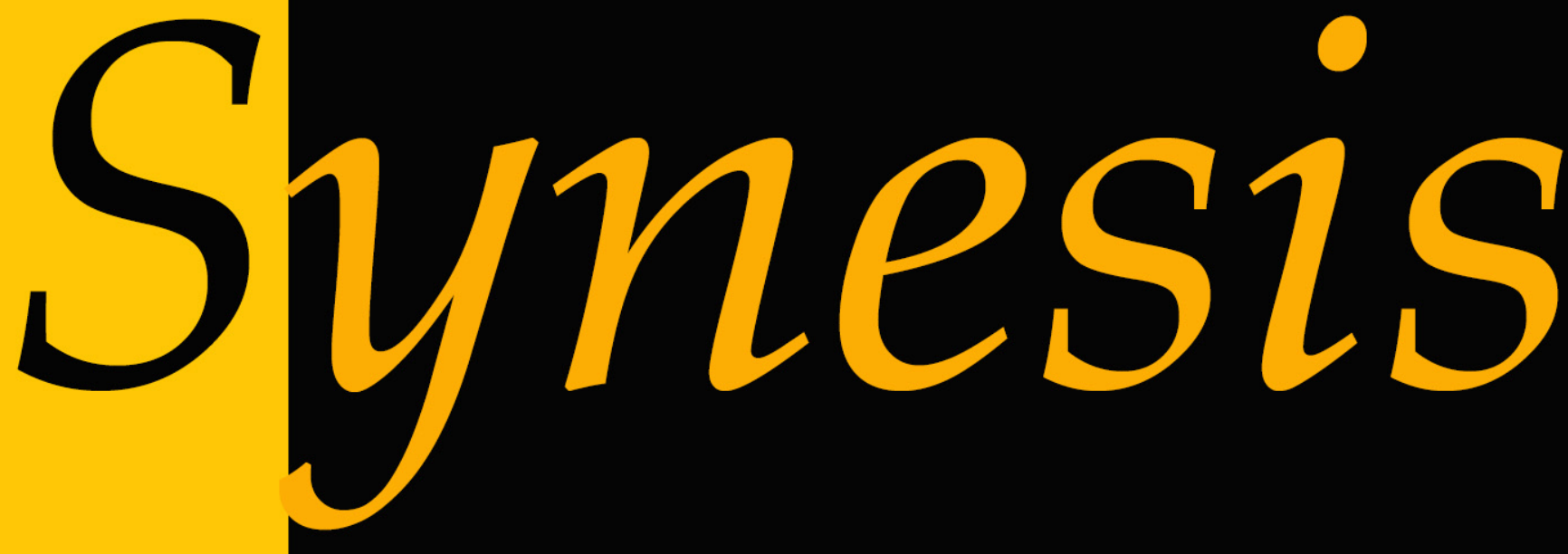

Revista do Centro de Teologia e Humanidades ISSN 1984-6754

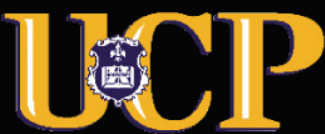




\title{
Reequacionamento da ConcepÇÃo de Natureza Humana como Fundamento do Direito Natural
}

\begin{abstract}
Alejandro Bugallo Alvarez ${ }^{1}$
Resumo: $\mathrm{O}$ texto parte do universo das críticas formuladas pelo positivismo ao direito natural como algo inerente à natureza e externo à vontade humana. Propõe a reconstrução do conceito de natureza na especificidade humana através de variáveis destacadas pelo pensamento moderno e contemporâneo: autodescoberta, autodeterminação que implica autonomia, autosuperação, autoconstrução e escolha dos mecanismos para a realização. O direito natural é a expressão ideal dos valores inerentes à dinâmica da natureza e demandados pela condição humana, formulados e compreendidos na dimensão do caráter relacional
\end{abstract}

Palavras-chave: autodeterminação, autosuperação, autoconstrução ,caráter relacional

Abstract: The text uses as starting point the universe of reviews formulated by Positivism to Natural Law as something inherent to Nature and external to human will. It proposes the reconstruction of the concept of Nature in human specificity through variables highlighted by modern and contemporary thought: self-discovery, self-determination which implies in autonomy, self-overcoming, self-construction, and choice of mechanisms for realization. Natural Law is the ideal expression of values inherent to the dynamics of Nature demanded by human condition, formulated and understood in the dimension of relacional nature.

$\overline{1}$ Doutor em Direito pela Universidade de Comillas, Espanha (revalidação pela UFSC). Professor Emérito da PUC-Rio.Professor de Teoria do Direito no Programa de Pós-Graduação em Direito da PUC-Rio e Professor Adjunto da UCP.

http://www.ucp.br/html/joomlaBR/synesis/synesis.htm 
Key words: self-determination,self-overcoming, selft-construction,relacional nature

\section{Introdução}

Dada a diversidade de concepções e fundamentos da teoria do direito natural, bem como de matizes na concepção de natureza e o universo das correspondentes críticas ${ }^{2}$ indaga-se, preliminarmente, sobre a conveniência e procedência em manter a expressão "direito natural" para preservar a tradição ou, seguindo a LYNCH, para identificar "um significado distinto e até contrário à tradição" e, desta forma, explicar e "construir ou reconstruir a teoria". ${ }^{3}$

A tarefa é arriscada e delicada porque, no dizer de CUNHA: $1^{\circ}$ "o pensamento único, hoje avassalador, já decidiu, com a petulante tirania do espírito,[...] que não existe nada de natural, e muito menos, a natureza humana"; $2^{\circ}$ que atributos como a prevalência do humano sobre os demais reinos da natureza, e sua diferença específica de "racionalidade, religiosidade, arte e da própria sociabilidade", encontram-se em crise razão da procedência

2 A história da Filosofia do Direito Natural oferece um quadro panorâmico da diversidade e especificidade das teorias do direito natural, resultantes não só da natureza como fundamento e suas diversas concepções, como também das dimensões destacadas da mesma.. Aliás a crítica, historicamente construída sobre o direito natural em seu fundamento e interpretação, mostra o mosaico das concepções e conseqüentes desqualificações. A este respeito e como indicativo, consultar: ALVAREZ, Alejandro B. Teses básicas do juspositivismo e suas críticas ao jusnaturalismo.Lex Humana, dez.2009. O universo dessas críticas, sejam elas de ordem metafísica, na medida em que se desqualifica qualquer fundamento transcendente, epistemológica, porquanto seus enunciados não são passiveis de aferição e controle, psicológica, na medida em que a natureza humana passa a se entendida como substrato das inclinações, emoções e paixões, ou ontológica., configuram fatores que estimulam a retomada do conceito de natureza humana, identificada através dos predicados fornecidos pela filosofia moderna e contemporânea

3 LYNCH, Alberto Benegas. Nuevo Examen del Iusnaturalismo. Revista Libertas IV:7, octubre 1987.Instituto Universitário ESEADE., p. 9. Parte-se do pressuposto de que, assim como não existe uma única teoria do direito natural, tampouco existe um único jusnaturalismo qualquer que seja o fator determinante:mítico-religioso, teleológico, metafísico, ontológico, racionalista. 
e sentido da indagação: "que é isso de natureza?. Que é isso de "Homem?".

A este respeito, secundando $\mathrm{LYNCH}$, é oportuno, por um lado, "lembrar que a diferença de critério sobre uma teoria não é argumento para negar sua validade" e, por outro, que "não se trata de estabelecer quem há de determinar em que consiste o direito natural, mas o que determina sua existência e, na hipótese afirmativa, qual o fator configurador ou constitutivo do mesmo. Nossos instrumentos mentais constituem a única ferramenta de que dispomos para conhecer a natureza do ser humano e as implicações dessas propriedades comuns da espécie". ${ }^{5}$ Por outro lado, temse como consolidado que qualquer que seja a perspectiva de abordagem e o nível de desenvolvimento da teoria do conhecimento e da ciência, bem como o campo de aplicação, que o conceito de verdade nem é essencial, nem absoluto; que os conceitos não descrevem, reproduzem ou representam a realidade, mas apenas são operacionais e em grande parte estipulativos. Desta forma, reconhecendo-se desvirtuamentos e a relatividade das construções sobre a natureza e especificamente sobre a natureza humana, é legítimo o empreendimento de reequacionamento do conceito de natureza humana, especialmente à luz da diversidade das ciências que tem o homem como objeto de análise, especialmente o leque de correntes de pensamento filosófico, da psicologia, da ética e da antropologia, bem como os avanços, conquistas e potencialidade da biologia, da neurociência e da biotecnologia.

4 CUNHA, Paulo Ferreira da .Natureza Humana e Filosofia Jurídica. http://www.hottopos. com/convenit $2 /$ nathump.htm Natureza humana, refere um conjunto de características, incluindo formas de agir e pensar, identificadas em todos os seres humanos pelas ciências que estudam a natureza humana, especialmente, pela antropologia, psicologia, biologia e filosofia e polarizadas em torno do eixo determinismo/liberdade, autonomia, emancipação.Os princípios que conformam a ciência moderna, além de reduzir a função da filosofia a uma reflexão sobre a ciência, desqualificam qualquer conhecimento que não obedece aos referenciais da verificabilidade, falseabilidade e verificação e consequentemente ao universo de objetos que não suportam o método científico. Cf. ALVAREZ,Alejandro B..Reabilitação da teoria do direito natural em John Finnis..Lumen Juris,2009.

LYNCH, Alberto Benegas,Ob.cit. p.10. 
Objetivo da proposta é a reconstrução do conceito de natureza humana, bem como a indicação de suas características e o perfil de sua dinâmica e consequentemente sua função em relação ao direito e, especificamente, ao direito natural.A elaboração do tema tem como ponto de partida a construção filosófico cultural acerca da natureza humana e sua contraposição e complementação pelos resultados das ciências que estudam a natureza: biologia, psicologia, antropologia, filosofia e ética. Implica, portanto, uma análise inter e transdisciplinar que ofereça como resultado, não só a conformação da natureza, como também sua dinâmica. Neste sentido, o trabalho não oferece um esquema fechado e acabado, mas apresenta indicadores que levam a inferir, ser possível falar de direito natural e formular-se uma teoria do direito natural que tenha como centro polarizador o homem e seja pelo mesmo formulado em seus princípios ou bens básicos e que resulte convincente individual e coletivamente, pela consistência e razoabilidade de construção e/ou pelo processo de aceitação.

Este artigo fixa apenas as coordenadas de uma abordagem preliminar, apenas indicativa e geral, que carece de pesquisas específicas nas diversas ciências referidas. Finalmente, é oportuno lembrar que a temática aqui apresentada integra um projeto mais abrangente em que se inserem: as "teses básicas do positivismo e suas críticas ao jusnaturalismo"; a "conexão existencial entre direito e moral em Lon Fuller" e a "reabilitação da teoria do direito natural em John M. Finnis": pressupostos e implicações. ${ }^{6}$

\section{2. $O$ conceito de natureza}

$\mathrm{Na}$ história do pensamento, as expressões direito natural e

6 Arespeito:ALVAREZ,Alejandro B..AConexão Existencial entre Direito e Moral em Lon Fuller. In:SALLES(org.) Ensaios sobre Processo, Justiça e Direitos Humanos II,2009; ALVAREZ,Alejandro B. Reabilitação da teoria do direito natural em John M.Finnis: pressupostos e implicações. Lumen Juris, 2009.

http://www.ucp.br/html/joomlaBR/synesis/synesis.htm 
jusnaturalismo, estão relacionadas diretamente com a natureza, mas tal relação foi rejeitada pelo positivismo jurídico, em razão das críticas formuladas à concepção de natureza como fundamento do direito natural, quer na formulação greco-romana ${ }^{7}$ quer na da escolástica e racionalista que, ao menos segundo interpretação da crítica, faziam referência às leis físicas ou ao estado natural e instintivo. Desta forma, lembra COTTA "difundiu-se a idéia de que [tais denominações]não tinham nenhum significado real e, portanto, nenhuma capacidade de interpretar a experiência jurídica concreta e de esclarecer o conceito de direito" e, conseqüentemente, sem qualquer validade teorética, ${ }^{8}$ o que contrasta com a atenção dada à natureza em seu significado para o homem na filosofia (Schelling) e especialmente na psicanálise $e^{9}$,razão porque " a idéia da possibilidade de um direito natural e, portanto, da legitimidade de uma teoria jusnaturalista não está desprovida de sentido nos dias de hoje". ${ }^{10} \mathrm{~A}$ questão central, está na identificação do critério em função do qual se constrói a teoria deste direito natural que COTTA sustenta dever ser centrado "na condição humana"."1

$7 \quad$ Nesta expressão incluem-se tanto as concepções pré-socráticas, quanto as resultantes da concepção de Sócrates, dos sofistas, dos filósofos do período sistemático [Platão e Aristóteles]e, ainda, do heleno-romano, como o estoicismo, em que a physis era entendida como natureza física, qualquer que fosse sua fundamentação.

8 COTTA, Sergio. Per un riesame delle nozioni di giusnaturalismo e diritto naturale. In.COTTA,Sergio. Diritto,Persona e Mondo Umano. Torino: G.Giappicelli Editore, 1989,p. 158.

9 Informa COTTA que “ a psicanálise, indagando o psiquismo humano, pós em evidência a diferença entre a natureza dos homens e dos animais", razão porque Jung afirmou que "a natureza humana não é zoomorfa nem interpretável no modelo zoológico, como confirma a antropoanálise de Biswanger". COTTA, Sergio .Ob.cit. p. 159.

10 COTTA, Sergio. Ob. Cit. P. 160. Na formulação do autor, esta ideia está corroborada: $1^{\circ}$ pela ação dos continuadores do jusnaturalismo clássico; $2^{\circ}$ no positivismo de Spencer, no historicismo de Dilthey, no marxismo pessoal de Erns Bloch ou no positivismo moderado de H.L.A. Hart que se refere a "um conteúdo mínimo do direito natural"; $3^{\circ}$ a identificação de elementos jusnaturalistas no existencialismo e no jusnaturalismo libertário de Foucault.Ob. cit. p. 161.

11 COTTA, Sergio. Ob.cit. p. 165. A este respeito, COTTA, sustenta:que não considera sólido: $1^{\circ} \mathrm{o}$ critério da pura referência à natureza; $2^{\circ} \mathrm{o}$ critério substancial dos conteúdos atribuídos ao direito natural porque são muito diversos entre os opostos, como no caso da escravidão; $3^{\circ} \mathrm{o}$ critério da forma social conforme ao direito natural; $4^{\circ}$ o critério da função do direito natural; $5^{\circ}$ o critério da indicação filosófica: racionalista ou vitalística. 


\subsection{Natureza humana e condição humana}

No contexto deste artigo o conceito de natureza refere-se à natureza humana, na linguagem de LYNCH, " à essência e propriedade característica do homem", entendido como perfectível. Pode falar-se em natureza específica do homem? Convergindo com critérios do conceito moderno de ciência, ROTHBARD, ${ }^{12}$ na formulação de LYNCH, sustenta que a natureza não está vinculada ao misticismo ou ao sobrenatural, mas : "dado que o mundo não consiste numa coisa homogênea, ou uma só entidade, segue-se que cada uma das coisas diferentes, possui atributos diferentes", do contrario seria a mesma coisa, razão porque pode concluir-se que tem distinta natureza e que quando coisas diversas interagem, ocorrerão "resultados específicos, delimitáveis e definíveis".

Em síntese: “ causas delimitáveis e definíveis, produzem efeitos delimitáveis e específicos". O comportamento de cada entidade "é a lei de sua natureza e esta lei inclui aquilo que ocorre como conseqüência das aludidas interações". O conjunto destas leis pode denominar-se "a estrutura da lei natural" [...] "se as maçãs, as pedras e as rosas tem natureza específica, é o homem a única entidade, o único ser que não tem natureza?”. E se o homem tem natureza, porque não pode estar aberta à observação e à reflexão racional? "Em tese, a ética da lei natural estabelece o que é bom ou o melhor para cada tipo de ente. A bondade é, por certo relativa á natureza da criatura de que se trate. No caso do homem "a ética da lei natural estabelece que a bondade ou a maldade pode determinar-se segundo o que convenha ou contradiga o que é melhor para a natureza do homem". ${ }^{13}$

12 ROTHBARD, M.N. The ethics of liberty. Humanities Press, 1982,pp 9-10.Apud LYNCH, Alberto Benegas,ob.cit.p.2.

13 LYNCH, Alberto Benegas,ob.cit.ibidem.

http://www.ucp.br/html/joomlaBR/synesis/synesis.htm 
Com a expressão condição humana ressalta-se a dimensão histórica da experiência humana, em contraposição á dimensão essencialista e constitutiva inerente á denominação natureza humana.

Ressalta LEIS: $:^{14} 1^{\circ}$ que a modernidade é marcada pela especialização, o que implica em perspectiva exclusivista, razão porque "as ciências sociais abordam seus objetos de estudo deixando entre parênteses suas concepções de natureza e, em particular, de natureza humana. Assim, com poucas exceções, os cientistas sociais arrepiam os cabelos quando ouvem falar de hipótese da existência de uma natureza humana". "As ciências sociais pretendem substituir ou transformar a natureza humana num construto ao gosto dos atores sociais". Porém, “Max Weber nos lembra que na atividade científica não estão em jogo as conseqüências para os seres humanos derivadas dos avanços do conhecimento, embora esses avanços possam trazer-lhes alegrias e tristezas. O que está em jogo é o próprio avanço do conhecimento científico"; ${ }^{15} 2^{\circ}$ que a reação dos cientistas sociais em geral aos descobrimentos da biologia, está associada à crença de que o conceito de natureza humana é construção da cultura em função da qual foram construídos os conceitos de ética, liberdade, autonomia e responsabilidade, mas que atualmente "há provas irrefutáveis de que, além das diversidades das sociedades, das culturas e das épocas, os seres humanos compartilham uma natureza humana que é fonte comum de comportamentos, atitudes e motivações" 16 e que " além da genética, a psicologia evolutiva é o campo de pesquisa que atualmente concentra maior quantidade de estudos empíricos que colocam em evidência a singularidade da natureza humana"; ${ }^{17} 3^{\circ}$ que a complexidade de relações e de abordagens pelas ciências, indica tendência

14 LEIS, Héctor Ricardo. O conflito entre a natureza humana e a condição humana no contexto atual das ciências sociais. Desenvolvimento e Meio Ambiente,n.10,pp 39-45, jul/dez 2004.

15 LEIS,Héctor Ricardo. Ob.cit. p. 41. A posição de Weber reproduz o ideal da neutralidade, expressão do conceito positivista de ciência.

16 DORTIER,Jean-François. La nature humaine redécouverte.Sciences Humanines,n.139,2003

17 LEIS,Héctor Ricardo. Ob.cit. p.42.

http://www.ucp.br/html/joomlaBR/synesis/synesis.htm 
para perspectivas de análise inter e transdisciplinares que implicam em abertura e neutralizam reducionismos. ${ }^{18}$

Nesta perspectiva transdisciplinar, equacionada como emergência totalizante $^{19}$ em que confluem discursos científicos sobre o homem, a antropologia: $1^{\circ}$ está no centro da filosofia porque seu objeto é o homem, por sua vez, objeto e fim da filosofia; $2^{\circ}$ será verdadeira se for científica, portanto utilizando métodos de investigação que permitam o controle dos enunciados $;{ }^{20} 3^{\circ}$ englobando a problemática da consciência, da subjetividade e relacional, com ênfase na alteridade ${ }^{21}$ e construída numa relação dialética em três momentos reciprocamente implicados: construção, desconstrução e reconstrução. ${ }^{22}$

\subsection{Concepção dinâmica e dimensões da natureza humana}

Face à ambigüidade inerente ao conceito de natureza humana e, consequentemente, ao ceticismo criado, oportuno lembrar que MORIN, ${ }^{23}$ na formulação de CUNHA, apoiado em dados e conjeturas recentes: $1^{\circ}$ sustenta que "a ambigüidade do Homem não lhe permite dizer se a sua essência reside na espécie, na sociedade ou no indivíduo", mas que os três

\footnotetext{
$18 \quad$ LEIS,Héctor Ricardo. Ob.cit. p. 40.

19 CARVALHO, Adalberto Dias de. A antropologia na encruzilhada das ciências humanas.p.7. http://ler.letras.up.pt/uploads/ficheiros/1686.pdf. Acessado 10/12/09.
}

20 CARVALHO, Adalberto Dias de. Ob.cit. ibidem.. A diversidade de discursos e concepções do homem, em razão das diversas facetas mostradas pelas ciências, é destacada por GOIS E SILVA, quem, independentemente do mérito de a antropologia oferecer uma ideia unitária de homem, sustenta que a antropologia é filosofia, defrontando-se com o desafio de responder à indagação que vamos fazer do homem? E o conceito de "humano" é elaborado a partir do elemento empírico, destacando os traços que o especificam; a linguagem, a capacidade de significação, a afetividade e, em geral, traços diferenciadores do humano.Cf GOIS E SILVA, Maria Cléa de. Condição humana e natureza humana.http://www. mundodosfilosofos.com.br/condiçao-humana-e-natureza- humana.htm . Acessado 12/12/09.

21 CARVALHO, Adalberto Dias de. Ob.cit. pp. 11-13.

22 CARVALHO, Adalberto Dias de. Ob.cit pp. 8-9.

23 MORIN, Edgar. Le Paradigme perdu: la nature humaine.Paris:Seuil,1973; MORIN, Edgar.O Paradigma Perdido.A Natureza Humana.Trad. Hermano Neves.Mem Martins, Europa-América, 1975.

http://www.ucp.br/html/joomlaBR/synesis/synesis.htm 
elementos estão implicados, de forma que "esta tríplice natureza é muito mais plástica e menos fixista que a oposição homem-animal"; $2^{\circ}$ deixa aberto o caminho para a ideia de uma universalidade de traços humanos, porquanto, não obstante "a diáspora etnocultural, todos os seres humanos, não apenas se manifestam fundamentalmente[...] pelos mesmos meios de expressão, mas também exprimem uma mesma natureza afetiva, e isto apesar dos floreados, das variações, dos estereótipos, das codificações, das ritualizações que as culturas introduziram no sorriso, no riso e nas lágrimas", razão porque o "relativismo induzido, a partir da ciência". parece começa, assim, a relativizar-se". ${ }^{24}$

A respeito da ênfase na espécie, duas referências são dignas de destaque: a primeira de KANT, em obra de $1784,{ }^{25}$ que na análise de XAVIER, delimita a concepção de natureza humana, entendida como o desenvolvimento progressivo, uniforme e ininterrupto, sob o enfoque individual e especialmente da espécie, das disposições do homem, e implica num projeto ou plano. ${ }^{26}$ Pressupõe uma teleologia da natureza, ressaltando que as disposições e capacitações inerentes ao ser, tanto as naturais, que condicionam o desenvolvimento, como as vinculadas à faculdade da razão e referentes ao plano de desenvolvimento racional, efetivam-se na espécie e não no indivíduo, conforme enunciado da primeira e segunda proposições. A segunda, pertinente a HABERMAS que vincula as práticas e soluções em função da espécie porque, em certas questões, como as pertinentes à genética, o eixo de análise deixa de ser exclusivamente o indivíduo e/ou a sociedade e tem como referência as gerações futuras, o que implica em dimensionar a

\footnotetext{
$24 \quad$ CUNHA,Paulo Ferreira da. Ob. Cit. p. 6.

25 Cf versão em português: .KANT,Immanuel. Ideia de uma história universal de um ponto de vista cosmopolita. São Paulo: Martins Fontes, 2003.

26 XAVIER,Leyserée Adrianne F. “Considerações da natureza humana em Kant e Freud e suas implicações para o desenvolvimento da civilização".

.http://www.psicanaliseefilosofia.com.br/adverbum/vol3 2/03_2_7natureza_humana kant_freud.pdf.
} 
autonomia e emancipação em função da espécie ${ }^{27}$. As diretrizes kantianas e habermasianas em relação à ênfase na espécie são recepcionadas por LEIS ao destacar que "os avanços contemporâneos da biologia não apenas obrigam a redefinir a ética”, deixando de priorizar o indivíduo como medida de todas as coisas e "colocando a espécie como um protagonista privilegiado da história humana", com o que são redefinidos também os fundamentos das ciências sociais.Noutros termos, afirma o autor, "aceito o desafio da biologia, temos que abandonar o universalismo construído a partir da categoria do indivíduo como membro da sociedade, para entrar num outro universalismo, de complexidade superior, construído a partir de um indivíduo pensado simultaneamente como membro da sociedade e da natureza". ${ }^{28}$

\subsubsection{Fatores da dinâmica da natureza}

\section{(i) Autosuperação}

Em razão da consciência de sua limitação e imperfeição e de sua potencialidade, o ser humano age visando "propósitos deliberados". "Está na natureza do ser humano que sua ação se dirija a passar de uma situação menos satisfatória a uma mais satisfatória" não sendo possível "conceber ação humana que não possua esta característica”. Portanto, a ação do sujeito explica-se por este motivo: ex ante, estima que estará melhor após a realização do ato. Ex post, ratificará ou retificará sua conclusão, segundo a valoração dos elementos, a partir do interesse pessoal de quem realiza os referidos atos, porquanto " o fim da ação e os meios utilizados serão escolhidos segundo seja a estrutura valorativa de quem age". ${ }^{29}$

27 HABERMAS, Jürgen.O futuro da natureza humana. A caminho de uma eugenia liberal. Trad. K.Janini \& E.A.Souza.São Paulo:Martins Fontes, 2004. Cf.LIMA,Aluísio Ferreira de. Resenha:Habermas,J(2004).O Futuro da natureza humana: a caminho de uma eugenia liberal. Encontro. Revista de Psicologia, vol. XI, No16, ano 2007.

28 LEIS, Héctor Ricardo. Ob.cit.p.44.

29 LYNCH, Alberto Benegas.Ob.cit.p. 2.

http://www.ucp.br/html/joomlaBR/synesis/synesis.htm 
Esta ideia de auto-superação resulta: $1^{\circ}$ da consciência que o homem tem de sua potencialidade para "desvendar a realidade" e que domina a natureza pelo conhecimento, razão porque saber é poder ( Francis Bacon). Por este motivo, procede à fixação dos padrões do conhecimento objetivo, dimensionado pelo fator quantitativo, em substituição ao qualitativo e pela exatidão, razão da importância da aferibilidade e controlabilidade dos enunciados(Galileu); mas ao mesmo tempo dá ênfase à razão como fundamento e essência do humano(Descartes) ${ }^{30} ; 2^{\circ}$ da consciência de que a dignidade do homem deriva de sua atividade, produto da razão ou orientada pela razão, no sentido da modernidade ${ }^{31} 3^{\circ}$ como resultado do antagonismo e confronto entre as tendências e aspirações dicotômicas: insociável sociabilidade; concórdia/discórdia; indolência/atividade. No fundo, implica na formulação de aspirações ( dimensão utópica), superação das insatisfações e concretização de aspirações, o que redunda em superações e realizações tópicas em constante renovação e reformulação. ${ }^{32}$

\section{(ii) Autodeterminação}

Por sua vez, "para que o indivíduo possa mover-se na direção desejada, é necessário que possa operar nesse sentido, livre de qualquer tipo de violência", noutros termos " é condição sine qua non que se respeito

\footnotetext{
30 BATISTELA,Airton Carlos \& BONETI,Lindomar Weber. A relação homem natureza no pensamento moderno.pp1101-1107.http://www.Pucpr.br/eventos/educere/educere2008anais/ pdf/1424 959.pdf.. A

31 A respeito da ideia moderna de razão, ressalta CHAUI,invocando a Historia da Filosofia de Hegel: $1^{\circ}$ que a filosofia é independente e só se submete à autoridade da razão,como faculdade plena de conhecimento; $2^{\circ}$ que a filosofia moderna realiza a descoberta da subjetividade "Reflexão ou Consciência de $\mathrm{Si}$ "; $3^{\circ}$ que todos os seres humanos são conscientes e racionais; $4^{\circ}$ que a razão,o pensamento, a capacidade de consciência para conhecer por si mesma a realidade natural e espiritual, denomina-se "Luz Natural"; $5^{\circ}$ que o Cogito ergo sum, é a primeira intuição evidente de que parte toda a filosofia moderna. CHAUI,Marilena. Filosofia moderna.http://www.cfh.ufsc.br/ wfil/chauí.htm. Acessão 12/12/09.

32 XAVIER,Leyserée Adriane Fritsch.Ob.cit. pp 169-170, a respeito da terceira e quarta proposição da de "Ideia de uma história universal de um ponto de vista cosmopolita".A ideia de autosuparação e emancipação também é inerente aos questionamentos nietzscheanos, na medida em que entende a condição e situação humana como luta contra todo tipo de servidão.A respeito cf.ARAUJO,Luís de. Nietzsche- que humanismo?. http://ler.letras.up.pt/uploads/ficheiros/1862.pdf
} 
sua liberdade" e, portanto, "a liberdade de dispor do próprio", o que "não só corresponde à natureza do ser humano, mas também este a requer para progredir".Portanto,"o direito como faculdade de usar e dispor do próprio e a liberdade são termos correlatos". "O ser humano é um animal racional e por sua racionalidade" pode conhecer e " selecionar distintos meios para a consecução de específicos fins". "A ausência de liberdade anula o atributo de racionalidade do ser humano contrariando sua natureza.A vida do ser humano carece de significado sem liberdade," a menos que consideremos que o simples fato de respirar constitui vida humana propriamente dita em lugar de simples vida vegetativa. Afirmamos que o ser humano é livre, o que implica o oposto a determinismo: uma máquina programada por seus genes e o meio ambiente que o circunda. ${ }^{33}$ Se por um lado, a ciência moderna, em contraposição aos referênciais que presidiam o pensamento na Idade Média, representou uma emancipação, por outro lado, em razão da vinculação operacional com as diretrizes da tecnologia, aprisiona o homem no pensamento calculista em detrimento da reflexão sobre o sentido da vida e da existência, razão porque constitui uma dimensão da autonomia e dos aspectos da crítica de Heidegger ao pensamento moderno. ${ }^{34}$

\section{(iii)Liberdade de escolha}

Por ser livre, pode o homem decidir-se a agir consoante os fatores hereditários e o meio ambiente, ou escolher a ação num sentido distinto. “Se se desconhece o livre arbítrio e se pretende tratar a ação humana do mesmo modo que as ciências naturais, não seria possível distinguir entre proposições falsas e verdadeiras. Se os pensamentos são ao cérebro o que a seiva à árvore, não haveria ideias verdadeiras ou falsas, do mesmo modo que não há seiva verdadeira ou falsa. Simplesmente é. Tampouco seria possível aludir ao que serve e ao que não serve a determinado objetivo, dado que a seleção de

\footnotetext{
$33 \quad$ LYNCH, Alberto Benegas.Ob.cit.p.3.

34 BATISTELA,Airton Carlos \& BONETI,Lindomar Weber,Ob.cit. pp 113-114.

http://www.ucp.br/html/joomlaBR/synesis/synesis.htm
} 
finalidades é incompatível com o determinismo". Por outro lado, "se não se pudesse distinguir entre idéias verdadeiras ou falsas para a seleção do fim, carece de sentido a operação mental ". ${ }^{35}$ A respeito, POPPER destaca:" tenho dito que o determinismo físico é um pesadelo[...] porque o mundo em seu conjunto, contudo o que nele há, é um imenso autômato e, portanto, nós não seriamos mais do que diminutas engrenagens ou, no máximo subautômatos dentro dele". Deste modo, destrói, concretamente, "a ideia de criatividade". ${ }^{36}$

$\mathrm{Na}$ linha deste entendimento sustenta CUNHA: $1^{\circ}$ "A natureza humana não há de confundir-se com determinação, com falta de liberdade. Pelo contrário, a liberdade é a essência da natureza humana. A inespecificidade instintiva é um outro nome para o livre-arbitrio. Onde os pessimistas ou niilistas, ou céticos lêem desproteção, porque pensado de forma individualista, vêem os comunitaristas sociabilidade. Onde os primeiros vêem ausência de natureza por debilidade instintiva, os segundos interpretam capacidade de orientar a sua existência, liberdade e maior dignidade" $.2^{\circ}$ Para o antropologismo existencialista, o Homem seria artificial, porque no fim das contas, não seria animal. Mas o animal assim concebido não seria rebaixado ao nível da máquina e, assim, da pura artificialidade?. Mas, "sem natureza ao contrário dos bichos, o Homem não seria inferior ao animal?". $3^{\circ}$ Necessário ponderar que "as perspectivas por que se encara o Homem são diversas. Não pode, por isso, chegar-se aos mesmos resultados. O paradigma zoológico, (da antropologia, da psicologia, da biologia, da etologia..) é profundamente diverso do paradigma da dignidade e das liberdades humanas", qualquer que seja sua fundamentação. "O homem do paradigma zoológico, sendo um animal débil, é mais animal, e menos homem. O da dignidade humana, define-se pelo seu próprio sonho, ou pelo seu próprio projeto".

"É que, não sendo a liberdade e a responsabilidade humanas um dado

\footnotetext{
$35 \quad$ LYNCH, Alberto Benegas.Ob.cit.ibidem.

36 POPPER,Karl. Conhecimento objetivo. Trad. Milton Amado. Belo Horizonte: Editora Itatiaia Ltda, 1975,pp.205-208.
} 
empírico como outros, as ciências empíricas, entre as quais a antropologia, pode não se pôr sequer os problemas, podem não interpretar os fatos de modo a conceber os conceitos de liberdade e de responsabilidade. $\mathrm{O}$ contrário, porém, ocorre com disciplinas normativas, como a Ética e o Direito". ${ }^{37}$

\section{(iv) Antideterminismo}

O conceito de liberdade surge como antítese ao determinismo e a experiência e aspiração à liberdade rejeita a relação necessária. A respeito da liberdade, BRANDEN destaca que "o livre arbítrio consiste numa ação, numa escolha básica: pensar ou não pensar[...]. A doutrina do determinismo encerra uma contradição central e insuperável- uma contradição epistemológica uma contradição implícita em todas as variedades de determinismo".Em contraposição, "a visão determinista do homem sustenta que se este pensa ou não, se conhece os fatos da realidade ou não, se localiza os fatos antes que suas inclinações ou suas inclinações antes que os fatos, tudo está determinado por forças que estão fora de seu controle". Os deterministas afirmam que "o que faz o homem o tinha que fazer, aquilo em que crê, o tinha que crer, se concentra sua mente em algo, tinha que concentrar-se"... "se somente se conduz pela razão, tinha que fazê-lo, se está guiado apenas pelo sentimento, tinha que fazê-lo, não podendo evitar aquelas situações".

Mas se isto fosse verdade, não haveria possibilidade de conhecimento conceitual para o homem. Nenhuma teoria seria mais plausível que outra, incluindo a teoria do determinismo psicológico [...]porquanto os partidários desta doutrina, não poderiam afirmar que sabem que sua teoria é verdadeira, apenas poderiam dizer que se sentem compelidos a crer dessa maneira[... dado que] são incapazes de julgar seus próprios juízos[...]. Uma mente que não é livre de verificar suas conclusões - uma mente cujo juízo não é livre - não tem maneira de diferenciar o que é lógico do ilógico [..e] não pode pretender possuir conhecimento de qualquer tipo; essa mente está

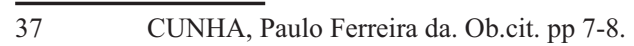

http://www.ucp.br/htmlljoomlaBR/synesis/synesis.htm 
desqualificada para tal coisa devido à sua própria "natureza". Portanto, cabe ponderar que o determinismo tem implicações éticas, não podendo falar-se em moralidade ou imoralidade de um ato se o sujeito não é responsável. ${ }^{38}$

\subsubsection{Sentido construtivo}

O caráter dinâmico da natureza humana evidencia-se por seu sentido construtivo. Aparentemente o histórico contrapõe-se ao natural, à natureza, porque enquanto a natureza relaciona-se com o significado do dado ou dado previamente à experiência humana e, portanto, não construído, o histórico relaciona-se com o cultural e, portanto construído. Esta contraposição significativa está consagrada na contraposição natureza e cultura. ${ }^{39}$ Aliás, uma das críticas do juspositivismo ao jusnaturalismo éa historicista, destacando que o direito não é um fenômeno natural, mas histórico. ${ }^{40}$ Todavia, a contribuição do historicismo, segundo COTTA, foi mostrar que "o homem, como indivíduo e como espécie, é a experiência do próprio histórico fazer e fazer-se fazendo. É a experiência de um devenir ativo" o que é sustentado por Ortega e Gaset, na consagrada expressão "Eu sou eu e minhas circunstâncias". ${ }^{41}$ O homem, portanto, não só é o centro da história, é agente da história, constrói a história e tem capacidade e é próprio de sua natureza fazer e fazer-se. A este respeito

38 BRANDEN.N. Fre Will,moral responsability and the law.The Libertarian alternative.T.R.Machan comp.,Nelson Hall,1974,pp 435-437.Apud: LYNCH,Alberto Benegas, ob.cit. pp.5-6.

39 Foi desenvolvida especialmente pelo culturalismo jurídico, com expressão na América latina, tendo como expoentes: Luis Recasens Siches, Carlos Cosio, Miguel Reale.. O culturalismo, tem sua origem na ênfase da dimensão cultural, na filosofia dos valores, e sua expressão e explicitação para o direito, em Rischmann e Dilthey.

40 Em síntese, o argumento positivista tem a seguinte formulação: o denominado direito natural ou é natural, e então não é direito, ou é direito, e então não é natural. Segundo COTTA, é "a primeira e culturalmente mais geral objeção à correta pensabilidade e teorização do direito natural"...."própria do historicismo filosófico devido á sua antropologia relativista, tanto na dimensão diacrônica como na sincrônica" cujo pensamento é contido na expressão "o homem não tem natureza, mas história". COTTA, Sergio.Diritto naturale e:ideale o vigente?.In: COTTA,Sergio. Diritto, Persona, Mondo Umano. Torino:Giappichelli Editore., 1989, p. 185.

COTTA, Sergio.Ob.cit. pp. 186;188. 
COTTA, afirma que "diferentemente de outros entes presentes no mundo circundante, somente ele é capaz de fazer e fazer-se segundo a experiência histórica. Porém, isto é possível porque tem uma natureza própria, diferente daquela dos outros entes [...] os quais não tem história, melhor não fazem história mas, eventualmente, a recebem do fazer do homem. Portanto, o emblemático aforismo do historicismo - o homem não tem natureza mas história - vai revestido do seguinte modo -" o homem tem história, porque tem uma própria natureza específica".[...] "Portanto, longe de comportar a negação da natureza humana, a historicidade tem o próprio fundamento e, portanto, o esclarecimento da sua mesma possibilidade de manifestar-se, nesta natureza" ${ }^{42}$. Neste sentido construtivo da natureza racional insere-se a idéia de Kant de que "o homem é um ser racional, cuja natureza, portanto, é caracterizada não pela necessidade mas pela racionalidade compreendente, julgadora e "prescrevente" ${ }^{43}$ e pela autonomia. Autonomia na própria criação, privilegiando as dimensões éticas e sociais, é o ponto de convergência entre existencialismo e marxismo, segundo os quais na formulação de MINAYO ${ }^{44}$ "o homem cria o seu próprio ser, pois o homem, através da história, gera sua própria natureza" razão porque este postulado deve marcar o equilíbrio na tensão ciência e humanismo, determinismo e autonomia.

\section{Caráter propositivo da natureza humana}

Em contraposição à crítica juspositivista que atribui, caráter normativo

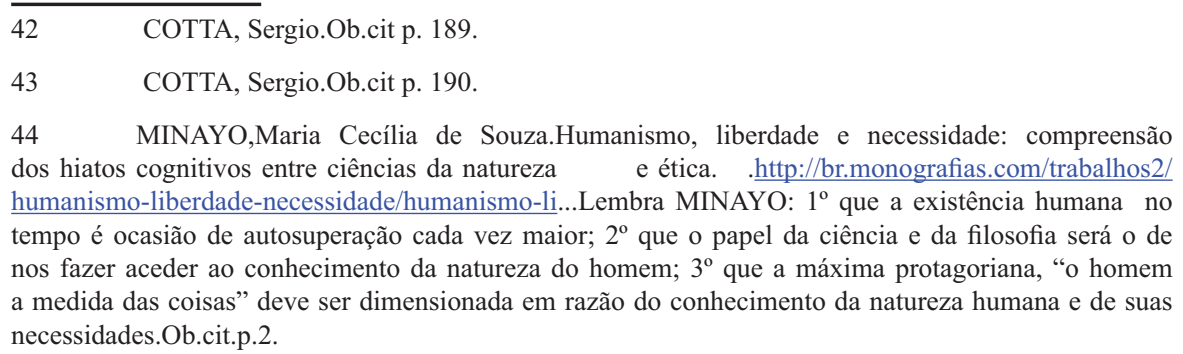
humanismo-liberdade-necessidade/humanismo-li...Lembra MINAYO: $1^{\circ}$ que a existência humana no tempo é ocasião de autosuperação cada vez maior; $2^{\circ}$ que o papel da ciência e da filosofia será o de nos fazer aceder ao conhecimento da natureza do homem; $3^{\circ}$ que a máxima protagoriana, "o homem a medida das coisas" deve ser dimensionada em razão do conhecimento da natureza humana e de suas necessidades.Ob.cit.p.2. 
à natureza, entendida como ente constitutivo, essencialista, instintivo e estático, pela vinculação do conceito de natureza com a condição humana, a natureza passa a ter caráter prospectivo porque passa a ser entendida como instância propositiva de critérios normativos. Parte-se do pressuposto de que o homem, que tem consciência de sua finitude e limitações, é construtivo e perfectível e que na busca da perfeição e realização estabelece metas e meios. Neste sentido e contrariando e superando o raciocínio contido na crítica positivista, ${ }^{45}$ sustenta COTTA: $1^{\circ}$ que "existe uma forma de entender o direito natural, sob o aspecto conteudístico que foge dessa condenação e é amplamente aceito pelo positivismo [...]: é o direito natural como direito puramente ideal", isto é expressão dos valores inerentes à natureza ou demandados pela condição humana visando à realização. É ideal, porque não vigente, e como propositivo, é direito, não conditum, mas condendum; $2^{\circ}$ que "Vale notar, que esta normação propositiva é riqueza própria da história, por ser experiência concreta da eficácia do direito vigente. Se se entende o direito natural como direito propositivo, e não vigente, não há razão para negar-lhe a qualificação de direito: não por acaso muitos modernos escritos de direito natural incluem na categoria do ius condendum, pela mesma razão, tantos escritos recentes de engenharia normativa". ${ }^{46}$

Oportuno lembrar que ao fazer referência à natureza humana ou à categoria ser homem, à qualificação de humanidade, estamos utilizando expressões em níveis de generalidade que somente poderão ser aquilatadas na confrontação da diversidade e pluralidade de análises sobre o ser-humano, mas que, como já mencionado, pressupõe as qualificações de racionalidade, perfectibilidade, autodeterminação e autoconstrução, a serem complementadas, entre outras, com a relacionalidade. ${ }^{47}$ Para efeitos

\footnotetext{
45 O argumento acima referido tem o seguinte enunciado: "se é natural não é direito, se é direito não é natural"

46 COTTA,Sergio. Ob.cit. p. 192.

47 Na contraposição desta variedade e diversidade de teorias antropológicas, COTTA refere, a título de exemplificação: a ambigüidade hobbesiana dividida entre instintividade originária e racionalidade 
analíticos, a questão é delimitar e precisar se o direito na sua positividade e a experiência jurídica no seu crítico fazer-se, revelam, de modo controlável, algumas características próprias do homem e de seu existir, cuja consistência será proporcional à correspondência e confirmação dos resultados pela análise antropológica, científica e filosofia ampliada e articulada.

Considera-se que a primeira característica constitutiva e operacional fundamental do ser humano é a relacionalidade. O homem por natureza é um ente em relação porque não há provas de que o homem, em qualquer tempo e lugar, esteja em condições de viver absolutamente só, mas precisa de comunicação, razão porque a transversalidade é prova segura da relacionalidade; por outro lado, o fenômeno e a experiência jurídica não é apenas um fenômeno transversal numa relação espaço temporal, mas também transhistórica porque não pertence a uma cultura, período histórico ou regime político mas é identificável em toda forma humana de existir, do que se infere que, a relacionalidade é inerente á condição humana. ${ }^{48}$

Esta relacionalidade revela-se em diversos níveis: (i) nível naturalístico , porquanto o $E u$ é resultado de ato ou processo relacional, dado que a estrutura genética, estritamente individual, é resultado da combinação dos cromosomas paternos e maternos; (ii) nível psicológico e psicoanalítico porquanto "o $E u$ não é autorreferencial baseado na conduta narcisista, causa da morte psíquica e talvez física. Por outro lado, o Eu reúne o equilíbrio psíquico. Na compreensão do originário e originante triângulo familiar [paimãe-filho], ordenando as desordenadas pulsões edípicas e superando as remoções. A referência a Freud é clara"; (iii) nível cultural porque o Eu não pensa nem é pensado, a não ser em relação a um pensamento, a uma cultura já pensada. É uma convicção antiga, reinvertida hoje da teoria popperiana do

calculista; a antropológica racionalística de um certo tranqüilizante iluminismo, na variante francesa e na utilitarista benthaniana ou do pragmatismo atual; da antropologia racional de Kant á dialética de Hegel; da materialistico -fabril de Marx à de Nietzsche, para a qual o homem é naturalmente vontade de potencia. Ob.cit. p. 201.

COTTA,Sergio. Ob.cit. p 202;187.

http://www.ucp.br/htmlljoomlaBR/synesis/synesis.htm 
mundo três, o da teoria mas também, por significativa precisão de Popper, o das instituições em sentido amplo da palavra, tanto lingüístico como jurídica.; (iv) nível do fazer e do agir: O Eu não é onipotente, nem mera condição de poder atuar por tudo quanto a fantasia imagina e o pensamento solicita projetar. Para projetar-se precisa da relação de cooperação; (v) nivel da consciência de si pois como mostrou Husserl nas Meditações Cartesianas, o $E u$ une a compreensão de si, na sua individualidade pessoal, somente na relação com o outro eu, mediante a qual está em condições de compreender a própria diversidade do outro eu e ao mesmo tempo a própria igualdade com isso quanto ao ser-homem, ao estatuído pela egoicidade. A autoconsciência verdadeira, nem psicoticamente nem idealmente narcisista, é relacional. ${ }^{49}$

Portanto pode inferir-se: $1^{\circ}$ que "a relação é constitutiva do $\boldsymbol{E} \boldsymbol{u}$ real" e do direito porquanto o aspecto relacional identifica-se e é pressuposto das diversas manifestações da normatividade; $2^{\circ}$ que o ser humano, ou seja, "a pessoa é relacional por natureza, numa continuidade existencial" nos dois aspectos inerentes ao seu ser, "o bionaturalístico da estrutura genética e o reflexivo espiritual da autoconsciência", bem como nas dimensões interna e externa, na dinâmica complexa do perceber e agir do unitário ser humano razão porque, a relacionalidade não é uma criação produzida pelo homem, como parecem proclamar, respectivamente, as antropologias do individualismo e do societarismo. ${ }^{50}$

Como resultado da dupla e recíproca transitividade interno-externa, reconhecida por Kant, infere COTTA que o direito positivo oferece seguro testemunho da segunda e mais profunda característica da natureza humana: "a complexa unidade do $\boldsymbol{E} \boldsymbol{u}$. O $\boldsymbol{E} \boldsymbol{u}$ não é um ente unidimensional[...]é unidade sintética, como ensinou a filosofia clássica do ser" e, embora não

\footnotetext{
49 COTTA, Sergio. Ob. Cit. pp. 203-204.

50 COTTA, Sergio. Ob. Cit. pp 204-206.A respeito do individualismo, referência a Hobbes, do societarismo, a Rouseau, Hegel, Marx, Tönies e a respeito da dimensão interna e externa, a Kant. 
há dados definitivos, os avanços da ciência bio-neuropsicológica tendem a confirmar a unidade psicossomática do indivíduo.

Neste contexto, conclui COTTA que: $1^{\circ}$ "a unidade sintética do $\boldsymbol{E} \boldsymbol{u}$ tem a mais evidente manifestação na união do corpo e alma espiritual, cuja separação é incompatível com a vida e a vitalidade do indivíduo", fato que, de alguma forma é confirmado pela determinação científica do evento da morte, através da coincidência entre a morte cerebral aferida pelo encefalograma e a cessação definitiva do ritmo cardíaco, o que tem um significado altamente simbólico: "com o primeiro tipifica-se o fim da capacidade de perceber e pensar, com o segundo o fim da capacidade de fazer subsistir as células corpóreas: o Eu é morto"; 51 2 $2^{\circ}$ que "se é verdade que a referencia á natureza humana constitui, em mais de um nível, a premissa constante, se bem que implícita, capaz de oferecer razões do exercício da juridicidade transhistórica e do direito histórico; se é verdade que esta natureza é validamente exprimível como estrutura sintético-relacional do $\boldsymbol{E} \boldsymbol{u}$ - então teremos chegado a um ponto firme - o fundamento ontológico do exercício transhistórico e histórico do direito é o $\mathrm{Eu}$ - sintético-relacional, cujo respeito[...] é a condição intranscindível do mundo humano. Portanto, a conformidade deste fundamento é o critério de juízo do caráter humano do direito positivo e portanto o critério determinante de sua obrigatoriedade, enquanto distinta da fatual constritividade". ${ }^{52}$

\section{Conclusão}

Em contraposição à polarização da ideia do direito natural na concepção de natureza e natureza humana enquanto resultantes de concepções filosóficas ou científicas, ontológicas e essencialistas, ou não, mas de excludência recíproca, razão da falácia naturalista, parte-se de um conceito

51 COTTA, Sergio. Ob. Cit.pp.206-207.

52 COTTA,Sergio. Ob.cit. p. 209.

http://www.ucp.br/htmlljoomlaBR/synesis/synesis.htm 
de natureza dinâmica e em construção, caracterizada pela autosuperação, a autodeterminação, autoconstrução.

A descoberta da conformação e explicitação das necessidades e aspirações da natureza humana, é resultado construído pelas ciências naturais, humanas e sociais, razão da transdisciplinariedade.

0 direito natural não está predeterminado, nem resulta imutável, mas implica em novos desdobramentos axiológicos, consoante os níveis de descoberta, aperfeiçoamento e de exigência da realização humana. Entendese que a formulação e explicitação do direito natural é tarefa da razão prática por processo de autodeterminação, assunto a ser desenvolvido.

É inerente ao reequacionamento proposto da natureza humana, o caráter instrumental do direito positivo em relação à realização do homem na complexidade de suas dimensões, o que implica na conexão entre direito e moral.

\section{Referências Bibliográficas}

ALVAREZ, Alejandro B. Teses básicas do juspositivismo e suas críticas ao jusnaturalismo.Lex Humana, dez.2009.

.Reabilitação da teoria do direito natural em John Finnis..Lumen Juris, 2009.

. Conexão Existencial entre Direito e Moral em Lon Fuller.In: SALLES,Sergio(Org.). Ensaios sobre Processo, Justiça e Direitos Humanos II,2009.

http://www.ucp.br/html/joomlaBR/synesis/synesis.htm 
BRANDEN.N. Fre Will,moral responsability and the law.The Libertarian alternative.T.R.Machan comp.,Nelson Hall,1974,pp 435-437.

CHAUI,Marilena.Filosofia moderna. http://www.cfh.ufsc.br/ wfil/chauí. htm.Acesso, 10/12/2009.

CARVALHO, Adalberto Dias de. A antropologia na encruzilhada das ciências humanas.

http://ler.letras.up.pt/uploads/ficheiros/1686.pdf. Acessado 10/12/09.

COTTA,Sergio. Per un riesame delle nozioni di giusnaturalismo e diritto naturale.In.COTTA,Sergio. Diritto, Persona e Mondo Umano. Torino: G.Giappicelli Editore, 1989.

CUNHA, Paulo Ferreira da. Natureza Humana e Filosofia Jurídica. http://www.hottopos.com/convenit2/nathump.htm

DORTIER,Jean-François.La nature humaine redécouverte.Sciences Humanines,n.139,2003.

GOIS E SILVA, Maria Cléa de. Condição humana e natureza humana. http://www.mundodosfilosofos.com.br/condicao-humana-e-naturezahumana.htm . Acessado 12/12/09.

HABERMAS, Jürgen.O futuro da natureza humana. A caminho de uma eugenia liberal.São Paulo:Martins Fontes, 2004.

KANT,Immanuel. Ideia de uma história universal de um ponto de vista cosmopolita.São Paulo: Martins Fontes, 2003.

LEIS, Héctor Ricardo. O conflito entre a natureza humana e a condição http://www.ucp.br/htmlljoomlaBR/synesis/synesis.htm 
humana no contexto atual das ciências sociais. Desenvolvimento e Meio Ambiente,n.10,pp 39-45, jul/dez 2004.

LYNCH, Alberto Benegas. Nuevo Examen del Iusnaturalismo. Revista Libertas IV:7, octubre 1987.Instituto Universitário ESEADE.

MINAYO,Maria Cecília de Souza.Humanismo, liberdade e necessidade: compreensão dos hiatos cognitivos entre ciências da natureza e ética. .http://br.monografias.com/trabalhos2/humanismo-liberdade-necessidade/ humanismo-li...

MORIN, Edgar. Le Paradigme perdu: la nature humaine.Paris:Seuil,1973.. .O Paradigma Perdido.A Natureza Humana.Trad. Hermano Neves.Mem Martins, Europa-América, 1975.

POPPER, Karl. Conhecimento objetivo. Trad. Milton Amado. Belo Horizonte: Editora Itatiaia Ltda, 1975,pp.205-208.

ROTHBARD, M.N. The ethics of liberty. Humanities Press, 1982.

XAVIER,Leyserée Adrianne F. "Considerações da natureza humana em Kant e Freud e suas implicações para o desenvolvimento da civilização”.

.http://www.psicanalise filosofia.com.br/adverbum/ vol3_2/03 2 2 7natureza_humana_kant_freud.pdf. 